\title{
Synthesis, Three-Dimensional Structure, Conformation and Correct Chemical Shift Assignment Determination of Pharmaceutical Molecules by NMR and Molecular Modeling
}

\author{
Sirlene O. F. de Azeredo, Edijane M. Sales and José D. Figueroa-Villar* \\ Grupo de Ressonância Magnética Nuclear e Química Medicinal, Departamento de Química, \\ Instituto Militar de Engenharia, Praça General Tibúrcio 80, 22290-270 Rio de Janeiro-RJ, Brazil
}

\begin{abstract}
This work includes the synthesis of phenanthrenequinone guanylhydrazone and phenanthro[9,10-e][1,2,4]triazin-3-amine to be tested as intercalate with DNA for treatment of cancer. The other synthesized product, 2-[(4-chlorophenylamino)methylene]malononitrile, was designed for future determination of its activity against leishmaniasis. A common problem about some articles on the literature is that some previously published compounds display error of their molecular structures. In this article it is shown the application of several procedures of nuclear magnetic resonance (NMR) to determine the complete molecular structure and the non questionable chemical shift assignment of the synthesized compounds, and also their analysis by molecular modeling to confirm the NMR results. To determine the capacity of pharmacological compounds to interact with biological targets is determined by docking. This work is to motivate the application of NMR and molecular modeling on organic synthesis, being a process that is very important for the study of the prepared compounds as interactions with biological targets by NMR.
\end{abstract}

Keywords: synthesis, phenanthrenequinone derivatives, NMR, molecular modeling, chemical shift determination, definitive molecular structure

\section{Introduction}

One of the most important information from compounds with biological activity is the determination of their complete three-dimensional and conformational structure, and also their definitive chemical shift assignment. This information is necessary to determine the interaction process of these pharmacological compounds with the biological targets, as enzymes, nucleic acids (DNA or RNA) and membrane receptors by nuclear magnetic resonance (NMR).

The molecular structure determination of pharmacological agents with biological targets is usually executed by X-ray diffraction, ${ }^{1}$ but sometimes, when crystallization of the complex is not possible, this method is not available. On the other hand, when the ligand-target complex possess mass lower than $70 \mathrm{kD}$, it is possible to determine their complete structure and its dynamic condition by NMR. ${ }^{2,3}$ However, if their mass targets are more than $100 \mathrm{kD}$, the NMR method is generally not

*e-mail: jdfv2009@gmail.com available for their complete ligand-target complex structure determination, but in this case the NMR can be used to determine the interaction of the ligand with the target, especially discovering which areas of the ligand are the most effective for interacting sessions with the target, ${ }^{4,5}$ being this the most effective method to study the interaction of pharmacological ligands with any type of targets. In order to determine by NMR which is the target site of interaction with the ligand it is necessary to execute the ligand competition with the previously described inhibitors, which is a process that confirms its interaction with the specific regions of the target, especially with the active sites of the enzymes. ${ }^{6-9}$

The normal NMR interaction analysis of pharmacological agents with biological targets are usually executed using water as solvent, and for this type of analysis the NMR method requires the complete information of the conformational structure and the definitive chemical shift of these pharmacological agent, being a process that allows the determination of quality and interaction with this agent. These NMR methods are based on the ${ }^{1} \mathrm{H}$ chemical shift, relaxation times $\left(\mathrm{T}_{1}\right.$ and $\left.\mathrm{T}_{2}\right)$, diffusion gradients and 
nuclear Overhauser effects (NOE).$^{7-9}$ For example, one of the most NMR used methods for this type of interaction studies is the saturation transfer difference (STD). ${ }^{10,11}$

Several compounds have been described in the literature with impropriate chemical shifts and wrong structures, sometimes leading to their incorrect interaction with biological targets. Therefore, the complete structure determination and chemical shift assignment of new potential pharmacological agents is very important for the study for their biological activity and interaction with targets.

In this article are described the synthesis, the NMR methods used to determine the complete and definitive three-dimensional, conformational and chemical shift assignment of pharmacological agents, and the confirmation by molecular modeling. The docking study is also important to determine if these compounds can interact with some biological targets, especially with some specific enzymes. This process is very important for the study of interaction from these agents with biological targets.

\section{Experimental}

\section{General experimental procedures}

Solvents and reagents were obtained from commercial companies (Sigma-Aldrich, Synth and Merck). Melting points were determined on a Fisher-Johns apparatus. The infrared spectra (IR) were measured using a Shimadzu 21 spectrometer, with samples prepared in tablets of anhydrous potassium bromide (KBr). The thin layer chromatography analyses were conducted using Merck silica gel 60 F254 aluminum sheets. The NMR spectra were obtained using a Varian 600 NMR spectrometer, with $5 \mathrm{~mm}$ tubes and using the DMSO- $d_{6}$ as solvent at $25{ }^{\circ} \mathrm{C}$. The solutions of these samples on the NMR tubes were used with $20 \mathrm{mg}$ at $600 \mu \mathrm{L}$. The NMR spectra were ${ }^{1} \mathrm{H},{ }^{13} \mathrm{C}$, attached proton test (APT), heteronuclear single quantum coherence ( $\mathrm{gHSQC}$ ), heteronuclear multiple bond coherence (gHMBC), correlation spectroscopy (COSY), total correlation spectroscopy (TOCSY) and gated decoupling ${ }^{13} \mathrm{C}$. The NMR frequency was $600 \mathrm{MHz}$ for the ${ }^{1} \mathrm{H}$ and $150 \mathrm{MHz}$ for the ${ }^{13} \mathrm{C}$. The molecular modeling calculations were executed with the Spartan'10 and using density functional theory (DFT) with the B3LYP and the M06 methods by 6-311G* basis set. ${ }^{12}$ These methods were used to determine the natural atomic charges (QNPA) for each atom, and the values of energy $\left(\mathrm{kJ} \mathrm{mol}^{-1}\right), \operatorname{PSA}\left(\AA^{2}\right)$, element volume $\left(\AA^{2}\right)$ and the dipole moment (Debye), and the calculated chemical shift of hydrogens and carbons to confirm with the NMR results. The docking study was performed with AutoDock Vina.
Synthesis and spectra of phenanthrenequinone guanylhydrazone (3)

In a $100 \mathrm{~mL}$ round bottom flask were added a mixture of phenanthrenequinone $(0.208 \mathrm{~g}, 1.0 \mathrm{mmol})$, aminoguanidine hydrochloride $(0.132 \mathrm{~g}, 1.2 \mathrm{mmol}), 20 \mathrm{~mL}$ ethanol $95 \%$ and a few drops of $\mathrm{HCl} 6 \mathrm{~mol} \mathrm{~L}^{-1}$. The reaction was refluxed for $4 \mathrm{~h}$. The solid product obtained after the solvent elimination by vacuum was washed with acetone and filtered to afford the pure solid. Orange solid; $93 \%$ yield; m.p.: $245-246{ }^{\circ} \mathrm{C}$; IR (KBr) $v_{\max } / \mathrm{cm}^{-1} 3033,1681,1634,1568,1509,1447$, 1278, 1167, 1020, 757; ${ }^{1} \mathrm{H}$ NMR (600 MHz, DMSO- $d_{6}$ ) $\delta 14.28$ (s, 1H, NH, H12), 8.89 (br s, 2H, $\mathrm{NH}_{2}, \mathrm{H} 14$ ), 8.64 (br s, 2H, $\left.\mathrm{NH}_{2}, \mathrm{H} 15\right), 8.48$ (d, 1H, J $8.0 \mathrm{~Hz}, \mathrm{CH}, \mathrm{H} 8$ ), 8.27 (d, 1H, J $7.5 \mathrm{~Hz}, \mathrm{CH}, \mathrm{H} 4), 8.18$ (d, 1H, J $7.5 \mathrm{~Hz}$, CH, H5), 8.13 (d, 1H, J $8.0 \mathrm{~Hz}, \mathrm{CH}, \mathrm{H} 1), 7.88$ (t, 1H, J $7.5 \mathrm{~Hz}, \mathrm{CH}, \mathrm{H} 3), 7.61$ (t, 1H, J $7.5 \mathrm{~Hz}, \mathrm{CH}, \mathrm{H} 2), 7.60$ (t, 1H, J $8.0 \mathrm{~Hz}, \mathrm{CH}, \mathrm{H} 6), 7.50$ (t, 1H, J $8.0 \mathrm{~Hz}, \mathrm{CH}, \mathrm{H} 7)$; ${ }^{13} \mathrm{C}$ NMR (150 MHz, DMSO- $\left.d_{6}\right) \delta 181.9(\mathrm{C}, \mathrm{C} 10), 156.4$ (C, C13), 139.3 (C, C4a), 136.3 (CH, C3), 134.9 (C, C9), 130.8 (CH, C6), 129.8 (C, C8a), 129.5 (C, C10a), 129.4 (C, C4b), 129.4 (CH, C7), 128.9 (CH, C2), 128.6 (CH, C1), 126.0 (CH, C8), 124.1 (CH, C4), 124.0 (CH, C6).

Synthesis and spectra of phenanthro[9,10-e][1,2,4]triazin3-amine (4)

In a $100 \mathrm{~mL}$ round bottom flask were added a mixture of phenanthrenequinone guanylhydrazone $(0.301 \mathrm{~g}, 1 \mathrm{mmol})$, $25 \mathrm{~mL}$ of distilled water and 15 drops of $\mathrm{NH}_{4} \mathrm{OH}$. The reaction was refluxed for $2 \mathrm{~h}$. The solid obtained was filtered and washed with distilled water to afford pure solid product. Yellow solid; 95\% yield; m.p.: 260-262 ${ }^{\circ} \mathrm{C}$; IR (KBr) $v_{\max } / \mathrm{cm}^{-1} 3469,3282,3120,3072,1633,1521,1444,1384$, 1026, 765, 723; ${ }^{1} \mathrm{H}$ NMR (600 MHz, DMSO- $\left.d_{6}\right) \delta 9.07$ (dd, $1 \mathrm{H}, J 7.1,1.9 \mathrm{~Hz}, \mathrm{CH}), 8.97$ (d, 1H, J 7.8 Hz, CH), 8.73 (d, 1H, J 7.8 Hz, CH), 8.69 (dd, 1H, J 7.2, $1.5 \mathrm{~Hz}, \mathrm{CH}), 7.89$ (t, 1H, J 7.8 Hz, CH), 7.75 (t, 1H, J 7.8 Hz, CH), 7.74 (t, $1 \mathrm{H}, J 7.2 \mathrm{~Hz}, \mathrm{CH}), 7.73(\mathrm{t}, 1 \mathrm{H}, J 7.1 \mathrm{~Hz}, \mathrm{CH}), 7.59$ (s, 2H, $\left.\mathrm{NH}_{2}\right) ;{ }^{13} \mathrm{C} \mathrm{NMR}\left(150 \mathrm{MHz}, \mathrm{DMSO}-d_{6}\right) \delta 162.2(\mathrm{C}), 143.1$ (C), $138.4(\mathrm{C}), 133.3(\mathrm{C}), 131.9(\mathrm{CH}), 128.4(\mathrm{CH}), 128.4$ (CH), $128.2(\mathrm{C}), 127.9(\mathrm{C}), 127.7(\mathrm{CH}), 127.5(\mathrm{C}), 125.3$ $(\mathrm{CH}), 123.5(\mathrm{CH}), 123.3(\mathrm{CH}), 120.0(\mathrm{CH})$.

Synthesis and spectra of 2-[(4-chlorophenylamino) methylene]malononitrile (5)

In a $100 \mathrm{~mL}$ round-bottomed flask were added $0.500 \mathrm{~g}$ (3.94 mmol) 4-chloroaniline, followed by addition of ethoxymethylenemalononitrile $0.250 \mathrm{~g}(2.04 \mathrm{mmol})$ dissolved in $30 \mathrm{~mL}$ of ethanol $95 \%$ and was heated under reflux for $3 \mathrm{~h}$. The precipitated product was filtered and washed with distilled water. Yellow solid; $76 \%$ yield; m.p. 252-254 ${ }^{\circ} \mathrm{C}$; IR (KBr) $v_{\max } / \mathrm{cm}^{-1} 3449,3294,3225,3024$, 
2368, 2214, 1659, 1589, 1489, 1335, 1180, 1095, 995, 818, 740, 548; ${ }^{1} \mathrm{H}$ NMR (600 MHz, DMSO- $\left.d_{6}\right) \delta 11.18(\mathrm{~s}, 1 \mathrm{H}$, $\mathrm{NH}), 8.51$ (s, 1H, CH), 7.45 (d, 2H, J 9.1 Hz, $2 \mathrm{CH}), 7.44$ $(\mathrm{d}, 2 \mathrm{H}, J 9.1 \mathrm{~Hz}, 2 \mathrm{CH}) ;{ }^{13} \mathrm{C}$ NMR $\left(150 \mathrm{MHz}\right.$, DMSO- $\left.d_{6}\right)$ $\delta 155.9(\mathrm{CH}), 138.2(\mathrm{C}), 129.3(\mathrm{CH}), 129.2(\mathrm{C}), 119.8$ $(\mathrm{CH}), 116.3(\mathrm{C}), 114.0(\mathrm{C}), 52.4(\mathrm{C})$.

\section{Results and Discussion}

The assignments of new potential pharmacological agents is normally executed with different one dimensional NMR spectra (1D), as ${ }^{1} \mathrm{H},{ }^{13} \mathrm{C},{ }^{19} \mathrm{~F}$ and ${ }^{15} \mathrm{~N}$, and with some dimensional (2D) spectra, as COSY, TOCSY, HSQC and HMBC. In general, the 1D spectra afford the ppm chemical shift values of all atoms, but to confirm the correct assignment of all atoms is fundamental the use of the 2D spectra. The COSY affords the coupling between all hydrogen atoms, but sometimes this method affords difficult results, especially when some ${ }^{1} \mathrm{H}$ signals are with superposition or with very similar chemical shift. ${ }^{13}$ For this reason it is important the use of the TOCSY method, which indicates the hydrogen groups that are part of different coupling systems. ${ }^{14}$

The HSQC affords one single bond correlation between ${ }^{1} \mathrm{H}$ with ${ }^{13} \mathrm{C},{ }^{19} \mathrm{~F},{ }^{15} \mathrm{~N}$ and other atoms. This methodology confirms which hydrogens are directly bounded to the other atoms, being this information important to partial determination of the chemical shifts. The other important spectrum is the HMBC, which displays the correlation of ${ }^{1} \mathrm{H}$ with the other atoms with two, three and four bond correlations, being very important to determine the chemical shift and position of all atoms, especially the quaternary carbons. This method is very important for the obtention of the complete chemical shift of all atoms from different compounds. Therefore, these 2D spectra are very important to determine the molecular position of all atoms. ${ }^{15}$

Interestingly, sometimes the application of these methods does not allow the complete assignment of the analyzed agents, being necessary the application of other methods to determine the complete coupling constants, a process that usually confirms the complete and non questionable chemical shift assignment. There are some methods than can be applied for this type of information, especially IPAP-HSQMBC, which is measurement for long-range heteronuclear coupling constants from spinstate selective multiplets. ${ }^{16}$ This method is very efficient, but sometimes requires several conditions for analysis. Other method, which was developed by our research group is the selective heteronuclear simultaneous short and long-range correlations (SHESSLOC), ${ }^{17}$ which is also appropriate. However, one of the simplest methods is the gated decoupling of ${ }^{13} \mathrm{C}$ NMR, which can also be applied to other atoms, as ${ }^{15} \mathrm{~N}$ and ${ }^{19} \mathrm{~F}$, being an easy application and affording very good results for the small molecules. However, this method is usually not used by all specialists on NMR. In general terms, the gated decoupling of ${ }^{13} \mathrm{C}$ NMR is very important to determine the chemical shift of all quaternary carbons, a process that have been used to confirm the structure and chemical shift of pharmacological agents. $^{18}$

In order to determine the three dimensional structure of molecules, despite the complete chemical shift assignment, it is also necessary the application of NOE. The NOE methods allow the calculation of dipolar coupling, a process that determines which hydrogens are close to other ones and the correlation distance without the participation of bonds. This methodology is very efficient to determine the diverse position of several hydrogens, allowing the confirmation of the three dimensional structure of these compounds. Another important procedure to confirm the three-dimensional structure of molecules is the application of molecular modeling. These NMR methodologies are described and applied for the non questionable assignment of molecules in this article.

The phenanthro[9,10-e][1,2,4]triazin-3-amine (4) was prepared with two reactions. Initially was selected phenanthrenequinone (1) to react with aminoguanidine hydrochloride (2), to form the phenanthrenequinone guanylhydrazone (3), which was selected as an agent for decreasing the cancer radiotherapy and for treatment of Alzheimer's disease. Finally, the product $\mathbf{3}$ was transformed to phenanthro[9,10-e][1,2,4]triazin-3-amine (4) by cyclization, as shown in Figure 1, which was also selected as intercalate to DNA.

The compound $\mathbf{3}$ was previously tested as intercalate of DNA and with condition to decrease $50 \%$ of the cancer radiotherapy. For this reason compound $\mathbf{4}$ was designed as DNA intercalate with the possibility to decrease the dose

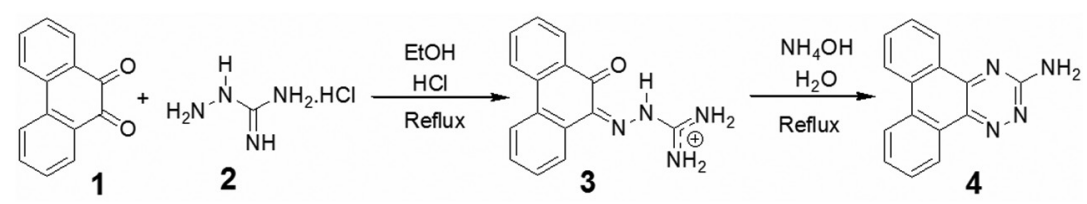

Figure 1. Synthesis of phenanthro[9,10-e][1,2,4]triazin-3-amine (4). 


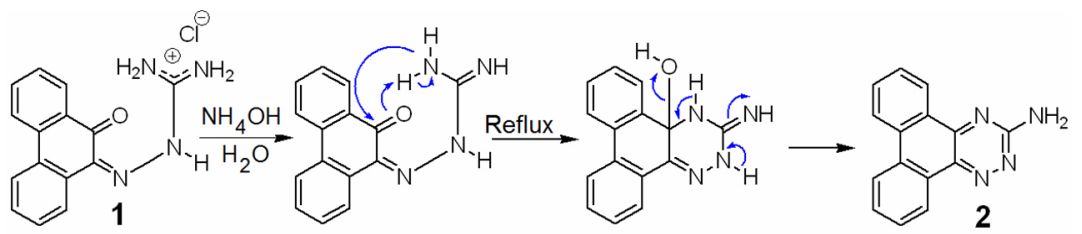

Figure 2. Mechanism of synthesis of phenanthro[9,10-e][1,2,4]triazin-3-amine (4).

Table 1. ${ }^{1} \mathrm{H}, \mathrm{COSY}$ and TOCSY of phenanthro[9,10-e $][1,2,4]$ triazin-3-amine $(\mathbf{4})$

\begin{tabular}{lccccc}
\hline$\delta_{\mathrm{H}}$ & Integration & Mult & $J_{\mathrm{HH}} / \mathrm{Hz}$ & COSY $^{\mathrm{a}}$ & TOCSY \\
\hline $9.07(\mathrm{H} 12)$ & $1 \mathrm{H}$ & $\mathrm{dd}$ & $7.1,1.9$ & $\mathbf{7 . 7 3}, 7.74$ & $9.07-8.69-7.74-7.75$ \\
$8.97(\mathrm{H} 5)$ & $1 \mathrm{H}$ & $\mathrm{d}$ & 7.8 & $\mathbf{7 . 7 5 , 7 . 8 9}$ & $8.97-8.73-7.89-7.75$ \\
$8.73(\mathrm{H} 8)$ & $1 \mathrm{H}$ & $\mathrm{d}$ & 7.8 & $8.69, \mathbf{7 . 8 9}$ & $8.73-8.97-7.89-7.75$ \\
$8.69(\mathrm{H} 9)$ & $1 \mathrm{H}$ & $\mathrm{dd}$ & $7.2,1.5$ & $8.73, \mathbf{7 . 7 4}$ & $8.69-9.07-7.74-7.75$ \\
$7.89(\mathrm{H} 13)$ & $1 \mathrm{H}$ & $\mathrm{t}$ & 7.8 & $\mathbf{8 . 7 3 , 7 . 7 5}$ & $7.89-8.97-8.73-7.75$ \\
$7.75(\mathrm{H} 6)$ & $1 \mathrm{H}$ & $\mathrm{t}$ & 7.8 & $\mathbf{8 . 9 7 , 7 . 8 9}$ & $7.75-8.97-8.73-7.89$ \\
$7.74(\mathrm{H} 10)$ & $1 \mathrm{H}$ & $\mathrm{t}$ & 7.2 & $\mathbf{8 . 6 9 , 7 . 7 3}$ & $7.74-9.07-8.69-7.73$ \\
$7.73(\mathrm{H} 11)$ & $1 \mathrm{H}$ & $\mathrm{s}$ & - & $\mathbf{9 . 0 7 , 7 . 7 4}$ & $7.73-9.07-8.69-7.74$ \\
$7.59(\mathrm{H} 13)$ & $2 \mathrm{H}$ & & - & - \\
\hline
\end{tabular}

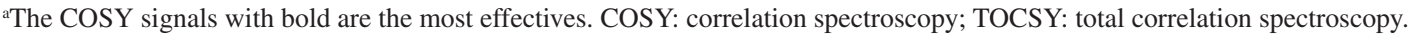

of cancer radiotherapy. Therefore, the complete chemical shift assignment of this compound is fundamental to study its interaction with DNA.

The mechanism of cyclization of phenathrenequinone guanylhydrazone $(3)$ to prepare phenanthro $[9,10-e][1,2,4]$ triazin-3-amine (4) is shown in Figure 2.

The initial NMR methods to obtain information for the chemical shift assignment of phenanthro[9,10-e][1,2,4] triazin-3-amine (4) were ${ }^{1} \mathrm{H}, \mathrm{COSY}$ and TOCSY, which results are shown in Table 1 . The ${ }^{13} \mathrm{C}$, gHSQC and gHMBC results are shown in Table 2.

The ${ }^{1} \mathrm{H}$ NMR spectrum affords the chemical shift and multiplicity of all ${ }^{1} \mathrm{H}$ signals and the integration procedure allows the determination of the number of hydrogen atoms on each signal. These results, as shown on columns 1-4 of Table 1, indicate that the hydrogen signals of 8.69 to $9.07 \mathrm{ppm}$ are hydrogens basically with only one other hydrogen at 3 bond distance, a process that allows ${ }^{3} J_{\mathrm{HH}}$ constants from 7.1 to $7.8 \mathrm{~Hz}$. Interestingly, only two of these hydrogens also display coupling with other hydrogens at 4 bond distances with ${ }^{4} J_{\mathrm{HH}}$ of 1.5 and $1.9 \mathrm{~Hz}$. This result indicates that the condition of the two benzyl rings containing hydrogens ( $\mathrm{A}$ and $\mathrm{B}$ ) are different, especially because the ligation condition of the aromatic ring containing the four nitrogen atoms with these two benzyl rings are different.

The COSY spectrum affords certain difficulty to determine the coupling of some hydrogen which display chemical shift very similar to other ones. In order to use better the COSY experiment is necessary to perform
Table 2. ${ }^{13} \mathrm{C}$, HSQC and HMBC of phenanthro[9,10-e][1,2,4]triazin3-amine (4)

\begin{tabular}{lcc}
\hline$\delta_{\mathrm{C}}$ & gHSQC & gHMBC $^{\mathrm{a}}$ \\
\hline $162.2(\mathrm{C} 3)$ & - & - \\
$143.1(\mathrm{C} 4 \mathrm{a})$ & - & $8.97,8.73$ \\
$138.4(\mathrm{C} 12 \mathrm{~b})$ & - & 9.07 \\
$133.3(\mathrm{C} 8 \mathrm{a})$ & - & $\mathbf{8 . 9 7}, 8.73,8.69, \mathbf{7 . 8 9}, 7.75$ \\
$131.9(\mathrm{C} 7)$ & 7.89 & $8.97,8.73,7.75$ \\
$128.4(\mathrm{C} 10)$ & 7.74 & $\mathbf{9 . 0 7}, 8.69$ \\
$128.4(\mathrm{C} 11)$ & 7.73 & $9.07, \mathbf{8 . 6 9}$ \\
$128.2(\mathrm{C} 8 \mathrm{~b})$ & - & $\mathbf{9 . 0 7}, 7.74,8.73,8.69$ \\
$127.9(\mathrm{C} 12 \mathrm{a})$ & - & $9.07,8.69,7.73$ \\
$127.7(\mathrm{C} 6)$ & 7.75 & $8.97,7.89,8.73$ \\
$127.5(\mathrm{C} 4 \mathrm{~b})$ & - & $8.97, \mathbf{8 . 7 3}, \mathbf{7 . 7 5}$ \\
$125.3(\mathrm{C} 5)$ & 8.97 & $\mathbf{7 . 8 9}, 8.73,7.75$ \\
$123.5(\mathrm{C} 8)$ & 8.73 & $7.89, \mathbf{7 . 7 5}$ \\
$123.3(\mathrm{C} 9)$ & 9.69 & $7.74,7.73$ \\
$122.0(\mathrm{C} 12)$ & 9.07 & $\mathbf{7 . 7 4 , 7 . 7 3}$ \\
\hline
\end{tabular}

${ }^{a}$ The signals with bold are the strong correlations, in normal font are average and in italic are the lowest ones. HSQC: heteronuclear single quantum coherence; HMBC: heteronuclear multiple bond coherence.

the spectrum with lower expansion and selecting all the coupling hydrogens. However, the best methodology is the use of TOCSY spectrum, which indicates that the ${ }^{1} \mathrm{H}$ signals from $9.07,8.69,7.74$ and $7.75 \mathrm{ppm}$ are the hydrogens from one of the two aromatic rings and 8.97, 8.73, 7.89 and $7.75 \mathrm{ppm}$ are from the other benzyl ring. This information 
is important to confirm the area of all hydrogen signals, especially because some of these signals are almost as similar superposition, for example, 7.74 and $7.73 \mathrm{ppm}$.

Despite being discovered which hydrogens are from each benzyl ring it is also important to determine which ring is $\mathrm{A}$ and $\mathrm{B}$, as shown on Figure 1. For this reason, it is necessary the obtention of the ${ }^{13} \mathrm{C}$ spectrum to determine the chemical shift of all carbons. The next process is the gHSQC spectrum to determine which hydrogens are directly bounded to the $\mathrm{CH}$ carbons. Finally, the gHMBC spectrum is used to determine the long range coupling of hydrogens with carbons. In this case, the $\mathrm{H}-\mathrm{C}$ coupling is the strongest at three bonds, being less with coupling at two bonds and very low or zero at four bonds. In general, when the coupling bounds are at 5 or more bonds, the coupling is normally zero.

Because the coupling between atoms depends from the electrons involved in the coupling bonds, these certain conditions lead to modification of the coupling constant. When atomic coupling occurs using two bonds, this twobond coupling $\left({ }^{2} J\right)$ is usually negative, while coupling at 3 bonds, named three-bond coupling $\left({ }^{3} J\right)$, is more positive. For this reason the ${ }^{2} J_{\mathrm{CH}}$ is much lower than ${ }^{3} J_{\mathrm{CH}}$, especially because with the two-bond coupling sometimes exists a mixture of positive and negative coupling, a process that sometimes leads to ${ }^{2} J_{\mathrm{CH}}=$ zero. For this reason, ${ }^{3} J_{\mathrm{CH}}$ is much more effective than ${ }^{2} J_{\mathrm{CH}}$. Another condition that decreases all coupling constants is the presence of electron attractive groups bounded to the atoms involved on the ligands for the coupling. This condition diminishes the density of electrons, a process that decreases the $J_{\mathrm{CH}}$. The coupling constants are also depending from the angles involved between the bonds with connection of the atoms, therefore, the conformation of the agents structure also affects the coupling constants. In general term, the ${ }^{3} J_{\mathrm{CH}}$ coupling depends on the angle, being major when the angle is $0^{\circ}$ or $180^{\circ}$ and very low when this angle decreases, which affords coupling constants of zero when the angle is of $90^{\circ}$.

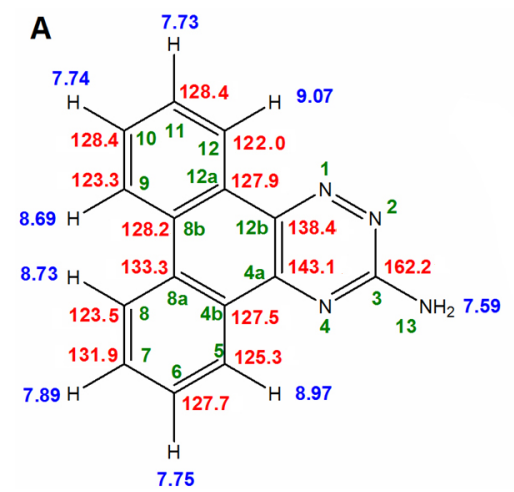

The gHMBC data, from column 2 of Table 2, confirm which carbons are directly with one bond to the respective hydrogens.

The gHMBC results, from column 3 of Table 2, are shown with different forms. The bold signals display strong ${ }^{1} \mathrm{H}-{ }^{13} \mathrm{C}$ interaction, usually being from three bonds. For example, 8.97 ppm from line 5 of Table 2, indicates that this hydrogen $(8.97 \mathrm{ppm})$ is at three bonds from the carbon of $133.3 \mathrm{ppm}$. All the other bold signals in Table 2 are also with this same condition. The hydrogen signals with normal size not marked in bold, from column 3 on Table 2, usually indicate a three bond correlation with their corresponding carbon, but sometimes could also correspond to a two bond correlation with their corresponding carbon. The hydrogen signals with the same size, but without being are low ${ }^{1} \mathrm{H}-{ }^{13} \mathrm{C}$ interaction results, but sometimes could be from three or two bond correlations, being more possible for the 3 bond correlation. The low results of these hydrogen signals, which are shown blue in structure, could be due to low coupling constants $\left({ }^{\mathrm{n}} J_{\mathrm{CH}}\right)$, a process that sometimes depends on the structure conformation, bonds rotation and the presence of electronegative or electropositive atoms bounded to the carbons from the involved coupling pathways. The complete assignment of phenanthro[9,10-e] $[1,2,4]$ triazin-3-amine (4) is shown in Figure 3. In this case it is used the possible chemical shifts of the quaternary carbons $4 \mathrm{a}$ and $12 \mathrm{~b}$, being selected $4 \mathrm{a}$ as the one with the higher chemical shift (143.1 ppm). Unfortunately, it could be possible that carbon $12 \mathrm{~b}$ could be of 143.1 ppm, a process that would exchange the chemical shift of compound 4 from A to B, as shown in Figure 3.

To confirm the assignment of structure A from Figure 3, are obtained from the spectra data of gHSQC and gHMBC. For example, the hydrogen of $9.07 \mathrm{ppm}$ is bounded to the carbon of $122.0 \mathrm{ppm}$ (gHSQC) and displays long length coupling with the carbons 138.4, 128.4, 128.4, 128.2 and 127.9, being the most strong with the carbons 128.4 and

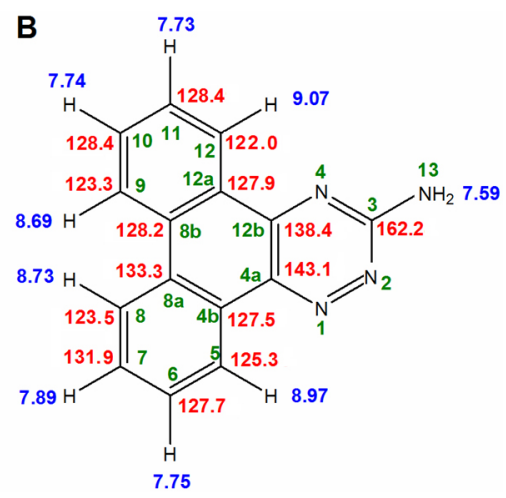

Figure 3. Two different assignment of phenanthro[9,10-e $][1,2,4]$ triazin-3-amine (4) (A and B). 
120.2 , indicating that it is at three bonds from carbon 128.4 , which is bounded to the hydrogen of $7.74 \mathrm{ppm}$, and with carbon 128.2 that is not bounded to any hydrogen. Interestingly, the $9.07 \mathrm{ppm}$ signal to the other quaternary carbon, $138.44 \mathrm{ppm}$, is not very strong, but that must be due to a three bonding distance. The other interactions are with the $\mathrm{CH}$ carbon 128.4, which is bounded to the hydrogen of $7.73 \mathrm{ppm}$, and with another quaternary carbon, $127.9 \mathrm{ppm}$, being at two bonds from the 9.07 hydrogen.

The only problem is if the chemical shift of carbons $4 \mathrm{a}$ and $12 \mathrm{~b}$ that could be exchanges, a process that could also exchange the position of atoms 1, 2, 3, 4 and 13, leading to structure $\mathrm{B}$. The aromatic carbons bounded with $\mathrm{C}-\mathrm{N}=\mathrm{N}$ or $\mathrm{C}-\mathrm{N}=\mathrm{C}$ could be with chemical shift 143.1 and 138.4 on the structure B. However, there is the possibility that the aromatic carbons bounded to $\mathrm{C}-\mathrm{N}=\mathrm{N}$ and $\mathrm{C}-\mathrm{N}=\mathrm{C}$ could also be of 143.1 and 138.4 on the structure B.

The possibility to confirm the structure of compound 4 is the study of the NMR spectra and comparison by molecular modeling, especially to determine which of the carbons $4 \mathrm{a}$ and $12 \mathrm{~b}$ displays lower electronic density, a process that could indicate which carbon contains the highest chemical shift.

The structure calculation of compound $\mathbf{4}$ using density functional with B3LYP and 6-311G*, affords the electronic density calculated with natural form, the molecular energy $\left(\mathrm{kJ} \mathrm{mol}^{-1}\right)$, polar surface area $\left(\mathrm{PSA}, \AA^{2}\right)$, element volume $\left(\AA^{2}\right)$ and their dipole moment (Debye), as shown in Table 3.

When the calculated electronic density of one atom is a positive value, this indicates that the number of electrons on this atom is low, leading to higher chemical shift. On the other hand, if the electronic density is negative, the number of electrons is higher and affords low chemical shift. When these numbers are positive, if they contain grate value, their chemical shift is higher. If the numbers are negative, when the negative number is major, the chemical shift is very low. For this reason the electronic density values indicate the possible chemical shifts of the carbons. These results display that the electronic density of the carbon bounded with two nitrogen atoms $(\mathrm{C}-\mathrm{N}=\mathrm{N}-)$ is 0.104 , and for the carbon bounded with only one nitrogen $(\mathrm{C}-\mathrm{N}=\mathrm{C}-)$ is 0.239 . The major electronic density $(0.239)$ is for a higher chemical shift, confirming that $4 \mathrm{a}$ is $143.1 \mathrm{ppm}$ and $12 \mathrm{~b}$
Table 3. Molecular modeling calculation results of compound (4)

\begin{tabular}{lll}
\hline Energy / $\left(\mathrm{kJ} \mathrm{mol}^{-1}\right)$ & -0.3035 \\
Area / $\AA^{2}$ & 249.35 \\
Volume / $\AA^{2}$ & 242.79 \\
PSA / $\AA^{2}$ & 50.120 \\
Dipole moment / Debye & 2.53 \\
Electronic charge & \\
C1 & -0.166 \\
C2 & -0.186 \\
C3 & -0.187 \\
C4 & -0.176 \\
C4a & -0.042 \\
C4b & -0.013 \\
C5 & -0.181 \\
C6 & -0.171 \\
C7 & -0.196 \\
C8 & -0.070 \\
C8a & -0.072 \\
C9 & 0.239 \\
C10 & 0.104 \\
C10a & -0.044 \\
C11 & 0.572 \\
\hline
\end{tabular}

PSA: polar surface area.

is of $138.4 \mathrm{ppm}$, indicating that the correct assignment of compound $\mathbf{4}$ is the structure B shown in Figure 3.

In some cases the complete assignment of certain molecules requires the determination of the ${ }^{\mathrm{n}} J_{\mathrm{CH}}$ in order to determine the position and chemical shift of some quaternary carbons. To determine the values of ${ }^{\mathrm{n}} J_{\mathrm{CH}}$ several procedures can be used, such as IPAP-HSQMBC, ${ }^{16}$ and SHESSLOC, ${ }^{17}$ but the simple and very easy to apply this method is the gated decoupling of ${ }^{13} \mathrm{C}$ NMR. ${ }^{18}$ One example of gated decoupling of ${ }^{13} \mathrm{C}$ NMR application is on compound 5, which was synthesized as shown in Figure 4.

The assignment of compound $\mathbf{5}$, which was selected for treatment of leishmaniasis, is generally simple, but the only problem is the definition of the chemical shift and position of carbons $\mathrm{C} 10$ and $\mathrm{C} 11$, which are very similar. The complete NMR results of compound $\mathbf{5}$ are shown in Tables 4 and 5. This compound was selected as inhibitor of

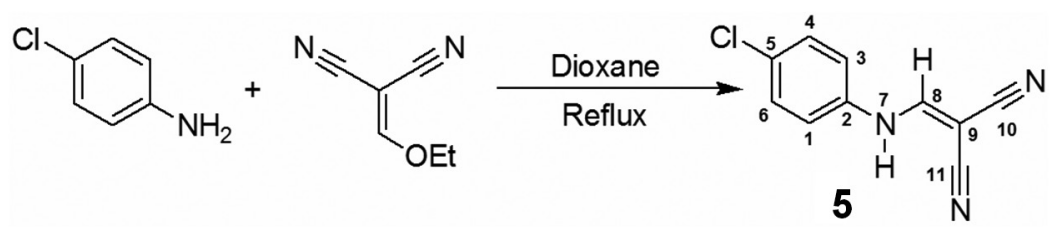

Figure 4. Synthesis of 2-[(4-chlorophenylamino)methylene]malononitrile (5). 
the enzyme nucleoside hydrolases (NH) from Leishmania donovani and Leishnamia chagasi, because we already discovered some of these agents. ${ }^{19}$

Table 4. ${ }^{1} \mathrm{H}$, gHSQC and gHMBC of 2-[(4-chlorophenylamino) methylene]malononitrile (5)

\begin{tabular}{lcc}
\hline$\delta_{\mathrm{H}}$ (Int., mult., $J$ Hz) & gHSQC & gHMBC $^{\mathrm{a}}$ \\
\hline $11.18(\mathrm{~s}, 1 \mathrm{H}, \mathrm{H} 7)$ & - & - \\
$8.51(\mathrm{~s}, 1 \mathrm{H}, \mathrm{H} 8)$ & 155.9 & $\mathbf{1 3 8 . 2}, \mathbf{1 1 6 . 3}, \mathbf{1 1 4 . 1}, \mathbf{5 2 . 4}$ \\
$7.45(\mathrm{~d}, 2 \mathrm{H}, 9.1, \mathrm{H} 2$ and H6) & 119.8 & $138.2,129.3, \mathbf{1 2 9 . 2}$ \\
7.44 (d, 2H, 9.1, H3 and H5) & 129.3 & $\mathbf{1 3 8 . 2}, 129.2,119.8$ \\
\hline
\end{tabular}

aThe signals with bold are the strong correlations, in normal font are average. HSQC: heteronuclear single quantum coherence; HMBC: heteronuclear multiple bond coherence.

Table 5. ${ }^{13} \mathrm{C}$, APT and gated decoupling of ${ }^{13} \mathrm{C}$ of of $2-[$ (4-chlorophenylamino) methylene]malononitrile (5)

\begin{tabular}{lccc}
\hline & \multirow{2}{*}{$\delta_{\mathrm{C}}$} & $\mathrm{APT}$ & \multicolumn{2}{c}{ Gated } \\
\cline { 3 - 4 } & & Mult. & ${ }^{\mathrm{n}} J_{\mathrm{CH}} / \mathrm{Hz}$ \\
\hline $155.9(\mathrm{C} 8)$ & $\mathrm{CH}$ & $\mathrm{d}$ & 176.9 \\
$138.2(\mathrm{C} 1)$ & $\mathrm{C}$ & $\mathrm{dt}$ & 6.9 and 4.6 \\
$129.3(\mathrm{C} 3$ and C5) & $\mathrm{CH}$ & $\mathrm{dd}$ & 167.9 and 4.6 \\
$129.2(\mathrm{C} 4)$ & $\mathrm{C}$ & $\mathrm{tm}$ & 8.7 \\
$119.8(\mathrm{C} 2$ and C6) & $\mathrm{CH}$ & $\mathrm{dd}$ & 165.4 and 5.8 \\
$116.3(\mathrm{C} 10)$ & $\mathrm{C}$ & $\mathrm{d}$ & 4.7 \\
$114.1(\mathrm{C} 11)$ & $\mathrm{C}$ & $\mathrm{d}$ & 10.4 \\
$52.4(\mathrm{C} 9)$ & $\mathrm{C}$ & $\mathrm{d}$ & 4.6 \\
\hline
\end{tabular}

APT: attached proton test.

The hydrogen $8.51 \mathrm{ppm}$, which is a simple signal because it is not bounded to the benzyl ring and with other hydrogens, but it is coupled with the carbons 116.3 and $114.1 \mathrm{ppm}$. The coupling condition between $8.51 \mathrm{ppm}$ with 116.3 and $114.1 \mathrm{ppm}$, because it is by three bonds, indicate that the respective ${ }^{3} J_{\mathrm{CH}}$ values depend on the conformation of the hydrogen with the two carbons, being at position cis of trans, as are shown in Figure 5.
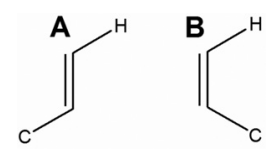

Figure 5. Conformation of three bound coupling of hydrogen with carbon.

The forms A and B from Figure 5 are linear cis and trans, respectively. The trans conformation allows the greater $\mathrm{H}-\mathrm{C}$ coupling than the cis conformation. When the system is planar, the angle between $\mathrm{C}$ and $\mathrm{H}$ is of $180^{\circ}$ in conformation $\mathrm{A}$ and of $0^{\circ}$ in conformation $\mathrm{B}$. Because the 116.3 and $114.1 \mathrm{ppm}$ carbons are only strongly coupled with $\mathrm{H}-8(8.51 \mathrm{ppm})$ as shown by gHMBC, it confirms that these carbons are from the $\mathrm{C} \equiv \mathrm{N}$ groups. On the other hand, the gated decoupling of ${ }^{13} \mathrm{C}$ NMR affords all the ${ }^{\mathrm{n}} J_{\mathrm{CH}}$ coupling constants, especially indicating that the ${ }^{3} J_{\mathrm{CH}}$ of the 116.3 and $114.1 \mathrm{ppm}$ are 4.7 and $10.4 \mathrm{~Hz}$, respectively. These results confirm that the carbon at the trans position about $\mathrm{H}-8$ is the $114.1 \mathrm{ppm}$ and the carbon at the cis position is the $116.3 \mathrm{ppm}$. Therefore, it is confirmed that the application of gated decoupling of ${ }^{13} \mathrm{C}$ NMR is very important to obtain the complete and non questionable chemical shift of quaternary carbons. Since hydrogens 8.51 and 7.44 display strong interaction with the quaternary carbon of 138.2 ppm by gHMBC, this condition indicates that the hydrogen 7.44 is close to this carbon and far from the $8.51 \mathrm{ppm}$. As the 7.54 hydrogen interacts strongly with the quaternary carbon of $129.3 \mathrm{ppm}$, which is bounded to the $\mathrm{Cl}$, this hydrogen is close to 8.51 . The complete assignment of compound $\mathbf{4}$ is shown in Figure 6 .

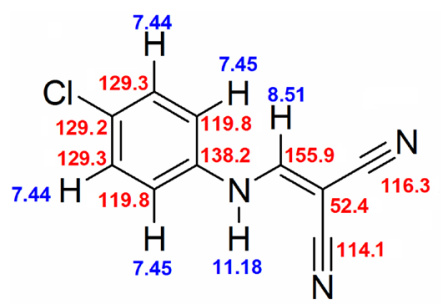

Figure 6. Complete assignment of 2-[(4-chlorophenylamino)methylene] malononitrile (5).

The molecular modeling calculation using density functional theory (DFT) with the B3LYP and the M06 method with 6-311-G* basis set, indicates the electronic atomic charges (QNPA) for each carbon, as shown in Table 6.

Table 6. Carbons molecular modeling calculation of electronic atomic charge from compound $\mathbf{5}$

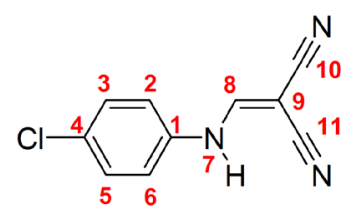

\begin{tabular}{lc}
\hline Carbon & Electronic charge \\
\hline C1 & 0.158 \\
C2 and C6 & -0.206 and -0.219 \\
C3 and C5 & -0.199 and -0.194 \\
C4 & -0.034 \\
C8 & 0.172 \\
C9 & -0.370 \\
C10 & 0.276 \\
C11 & 0.285 \\
\hline
\end{tabular}


The electronic condensation on each atom indicates their possible chemical shift. When the electronic concentration is major or lower, the chemical shift is lower or major, respectively. The carbons electronic charge from compound 5 are between -0.219 and +0.285 , being the negative values with major electronic concentration, and the positive ones with lower concentration. In this case, the $\mathrm{C} \equiv \mathrm{N}$ carbon of major electronic charge display electronic charges of 0.276 of $116.3 \mathrm{ppm}$ and the other one 0.285 with $114.1 \mathrm{ppm}$. The definitive chemical shift of these carbons is determined by all NMR methods, being also important the gated decoupling ${ }^{13} \mathrm{C}$ and molecular modeling.

The study of the potential capacity of these compounds to interact with the selected biological targets was executed by docking with AutoDock Vina. The interaction of compound $\mathbf{4}$ was selected to DNA. For this topic it was used the Drew-Dickerson-Dodecamer (DDD), and the docking indicated that this compound is an appropriate intercalate to DNA, as shown in Figure 7.

This result indicates that compound $\mathbf{4}$ could be used as an agent to decrease the dose of cancer radiotherapy, in order to diminish the negative effects of radiotherapy to other human cells. This compound interacts better with the groups deoxydenosine 5'-monophosphate (A) and deoxythymidine 5'-nonophosphate (T) of DDD.

The docking study of compound $\mathbf{5}$ as inhibitor of the enzyme nucleoside hydrolase from Leishmania donovani $(\mathrm{NH})$ is shown in Figure 8.

This result indicates that the $\mathrm{CN}$ groups of compound $\mathbf{5}$ interact with the amino acids Asp14, Th4128, Asn168 and the $\mathrm{Ca}^{2+}$ of this enzyme. On the other hand, the $\mathrm{NH}$ group interacts with Gly 12 and the aromatic ring displays $\pi$-stacking with Phe167. For this reason, this compound could display activity against leishmaniasis.

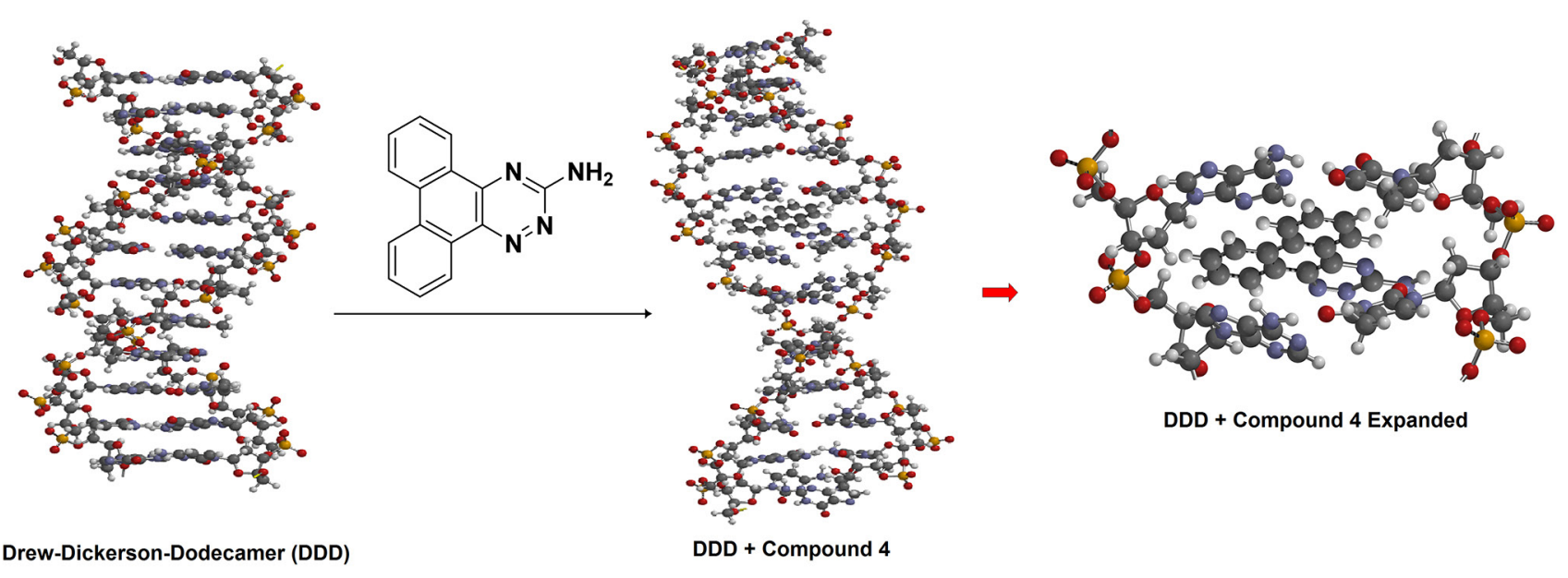

Figure 7. Docking of compound 4 with Drew-Dickerson-Dodecamer (DDD).
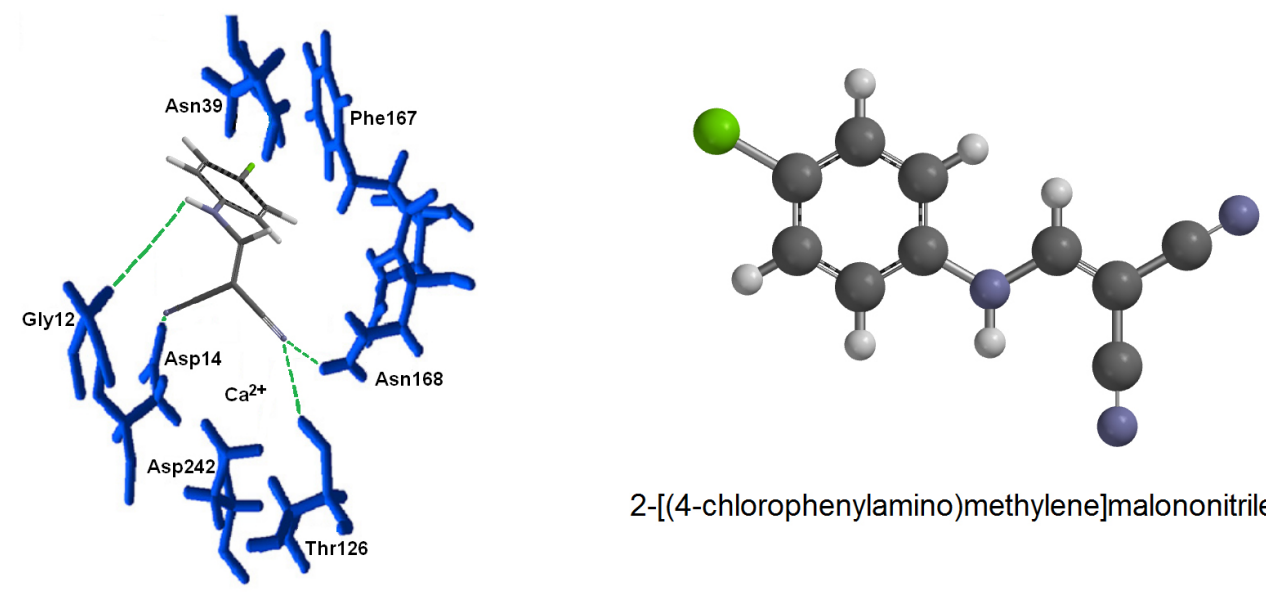

2-[(4-chlorophenylamino)methylene]malononitrile (5)

\section{Active site of Nucleoside Hydrolase + Compound $\mathbf{5}$}

Figure 8. Docking study of the interaction of compound $\mathbf{5}$ with nucleoside hydrolase (NH). 
The biological texts of these compounds will be performed on the future, and also with other similar compounds against cancer and Leishmania.

\section{Conclusions}

The determination of the non questionable and complete chemical shift assignment of potential pharmacological agents is very necessary to determine their condition of interaction with the biological targets involved on their biological activity. This information can be used for inhibition of enzymes and interaction with DNA, being a process to determine which areas of these pharmacological agents are interacting with the targets, a process that allows the design of new agents.

In general terms, the methods to definitely confirm the structure and chemical shift of all compounds must be executed by several NMR spectra and molecular modeling calculations, being these procedures very important to confirm the definitive structure of the obtained compounds prepared by synthesis. This condition is to motivate the complete structure and chemical shift assignment of all new synthesized compounds, in order to confirm their condition. This procedure is also confirmed by molecular modeling.

The use of docking is also very important to also determine the capacity of compounds to interact with biological targets, a process that also confirms their capacity as pharmacological agents.

In the future, the compound $\mathbf{4}$ will be tested as DNA intercalate and to determine the decrease of the cancer radiotherapy. This compound, being planar and with aromatic rings, it can interact with the elements of DNA by $\pi$-stacking, and the $\mathrm{NH}_{2}$ group could interact with the $-\mathrm{NH},-\mathrm{OH}$ and phosphate groups. The compound $\mathbf{5}$, which was designed as inhibitor of the enzyme nucleoside hydrolases (NH) for Leishmania, being a process that its groups $\mathrm{CN}$ and $\mathrm{NH}$ could interact with the $\mathrm{Ca}^{2+}$ atoms of the active site of this enzyme, and the chlorinated benzyl group could also interact with some of the amino acids of this enzyme. The biological tests of these compounds will be executed on the future.

\section{Supplementary Information}

The supplementary data of NMR spectra ${ }^{1} \mathrm{H},{ }^{13} \mathrm{C}$, gHSQC, gHMBC, COSY, gated decoupling ${ }^{13} \mathrm{C}$ and TOCSY, their molecular modeling structures and the NMR assignment by molecular modeling of compound $\mathbf{4}$ are available free of charge at http://jbcs.org.br as a PDF file.

\section{Acknowledgments}

We appreciate the financial support afforded by CAPES, $\mathrm{CNPq}$ and INBEB.

\section{References}

1. Bunaciu, A. A.; Udristioiu, E. G. ; Aboul-Enein, H. Y.; Crit. Rev. Anal. Chem. 2015, 45289.

2. Pervushin, K.; Riek, R.; Wider, G.; Wuthrich, K.; Proc. Natl. Acad. Sci. U. S. A. 1997, 94, 12366.

3. Wider, G.; Wuthrich, K.; Curr. Opin. Struct. Biol. 1999, 9, 594.

4. Rossi, C.; Donati, A.; Sansoni, M. R.; Chem. Phys. Lett. 1992, 189, 278.

5. Figueroa-Villar, J. D.; Tinoco, L. W.; Curr. Top. Med. Chem. 2009, 9, 811 .

6. Coles, M.; Heller, M.; Kessler, K.; Drug Discovery Today 2003, $8,803$.

7. Soares, S. F. D. X.; Vieira, A. A.; Delfino, R. T.; Figueroa-Villar, J. D.; Bioorg. Med. Chem. 2013, 21, 5923.

8. Palmer, A. G.; Acc. Chem. Res. 2015, 48, 457.

9. Richards, M. R.; Brant, M. G.; Boulanger, M. J.; Cairo, C. W.; Wulff, J. E.; MedChemComm 2014, 5, 1483.

10. Viegas, A.; Manso, J.; Nobrega, F. L.; Cabrita, E. J.; J. Chem. Educ. 2011, 88, 990.

11. Cabeça, L. F.; Pomini, A. M.; Cruz, P. L. R.; Marsaioli, A. J.; J. Braz. Chem. Soc. 2011, 4, 702.

12. Shao, Y.; Molnar, L. F.; Jung, Y.; Kussmann, J.; Ochsenfeld, C.; Brown, S. T.; Gilbert, A. T. B.; Slipchenko, L. V.; Levchenko, S. V.; O’Neill, D. P.; DiStasio, J. R. A.; Lochan, R. C.; Wang, T.; Beran, G. J. O.; Besley, N. A.; Herbert, J. M.; Lin, C. Y.; Van Voorhis, T.; Chien, S. H.; Sodt, A.; Steele, R. P.; Rassolov, V. A.; Maslen, P. E.; Korambath, P. P.; Adamson, R. D.; Austin, B.; Baker, J.; Byrd, E. F. C.; Dachsel, H.; Doerksen, R. J.; Dreuw, A.; Dunietz, B. D.; Dutoi, A. D.; Furlani, T. R.; Gwaltney, S. R.; Heyden, A.; Hirata, S.; Hsu, C.-P.; Kedziora, G.; Khalliulin, R. Z.; Klunzinger, P.; Lee, A. M.; Lee, M. S.; Liang, W. Z.; Lotan, I.; Nair, N.; Peters, B.; Proynov, E. I.; Pieniazek, P. A.; Rhee, Y. M.; Ritchie, J.; Rosta, E.; Sherrill, C. D.; Simmonett, A. C.; Subotnik, J. E.; Woodcock III, H. L.; Zhang, W.; Bell, A. T.; Chakraborty, A. K.; Chipman, D. M.; Keil, F. J.; Warshel, A.; Hehre, W. J.; Schaefer, H. F.; Kong, J.; Krylov, A. I.; Gill, P. M. W.; Head-Gordon, M.; Phys. Chem. Chem. Phys. 2006, 8, 3172 .

13. Kessler, H.; Muller, A.; Oschkinat, H.; Magn. Reson. Chem. 1985, 23, 844 .

14. Wollborn, U.; Leibfritz, D.; J. Magn. Reson. 1991, 3, 653.

15. Parella, T.; Espinosa, J. F.; Prog. Nucl. Magn. Reson. Spectrosc. 2013, 73, 17.

16. Gil, S.; Espinosa, J. F.; Parella, T.; J. Magn. Reson. 2010, 207, 312. 
17. Nascimento, C. J.; Figueroa-Villar, J. D.; J. Magn. Reson. 2007, $187,126$.

18. Figueroa-Villar, J. D.; Appl. Magn. Reson. 2015, 46, 607.

19. Rennó, M. N.; França, T. C. C.; Nico, D.; Palatnik-de-Sousa,
C. B,; Tinoco, L. W.; Figueroa-Villar, J. D.; Eur. J. Med. Chem. 2012, 56, 301 .

Submitted: April 29, 2016

Published online: August 31, 2016 